status, cited the welfare of their children as a prime reason for staying in an abusive relationship.

Parental separation is considered a risk factor for poor mental health in the offspring. Therefore parents staying together in marriage may protect their children from mental health problems. However, in our study children of $31 \%$ of the victims had witnessed the abuse. It has been demonstrated that emotional abuse in childhood has a major impact on adult mental health (Edwards et al, 2003). Kumar et al found that $56 \%$ of women who had been abused had poor mental health. Since parental mental disorder has been shown to be associated with psychological problems in the offspring (Rutter, 1966), it is doubtful whether staying in an abusive marriage is beneficial for the children.

Studies in developing countries repeatedly confirm that domestic violence is a problem that cannot be ignored and will significantly affect the mental health of future generations. We appreciate the efforts of Kumar et al in highlighting this issue and we consider the time has come to prevent this form of abuse in developing countries.

Edwards, V. J., Holden, G. W., Felitti, V. J., et al (2003) Relationship between multiple forms of childhood maltreatment and adult mental health in community respondents: results from the adverse childhood experience study. American Journal of Psychiatry, 160, 1453-1460.

Kumar, S., Jeyaseelan, L., Suresh, S., et al (2005) Domestic violence and its mental health correlates in Indian women. British Journal of Psychiatry, 187, 62-67.

Rutter, M. (1966) Children of Sick Parents: An Environmental and Psychiatric Study (Maudsley Monographs no. 16). Oxford: Oxford University Press.

Subramaniam, P. \& Sivayogan, S. (200I) The prevalence and pattern of wife beating in the Trincomalee district in eastern Sri Lanka. Southeast Asian Journal of Tropical Medicine and Public Health, 32. 186-195.

K. A. L. A. Kuruppuarachchi Department of Psychiatry, Faculty of Medicine, University of Kelaniya, Ragama, Sri Lanka.

E-mail: lalithkuruppu@lycos.com

L.T.Wijeratne Department of Psychiatry,

University of Kelaniya, Ragama, Sri Lanka

\section{Epidemiological approach to predicting psychiatric risk in the military}

The warlike events resulting from terrorism in London on 7 July 2005 have again shown the importance of enhancing human resilience and give special relevance to
June's issue of the Journal. In a marvellous overview, Professor Wessely (2005) gave us his thoughts concerning psychological trauma, modern psychiatric trauma concepts, and the emergence of new syndromes, especially in military settings.

Contrary to Professor Wessely, we are convinced that longitudinal selection provides considerable advantages for psychiatric risk management. Despite the unsatisfactory American experience with personality testing during the Second World War (Jones et al, 2003) our main field of activities is cohort-based psychometric screening and prediction models. In 2002, the Swiss Armed Forces assigned us to investigate new methods to predict psychiatric disorders in servicemen. At first we were sceptical that such a task could be fulfilled. However, we found prediction models to forecast outcome in emergency patients in the medical literature (Tuhrim et al, 1988). Furthermore, personality seemed to play some part in the outcome of somatic disorders (Eysenck, 1988) and suicide seemed predictable from demographic variables (Holinger et al, 1988). Consequently we investigated how these techniques could be transferred to psychiatry.

In a small preliminary (2002) study we screened 3000 recruits on their first day of basic training and followed their medical records for psychiatric problems. Based on clinical-epidemiological knowledge, logistic regression helped us to create a robust multivariable model. Since 2003 the model has been used by the Swiss Armed Forces for recruitment. The model compares each conscript with about 30000 servicemen. As a result, subsequent psychiatric discharge on the grounds of receiving an ICD-10 (World Health Organization, 1992) diagnosis was significantly lowered by a factor of 3 (or $72 \%$ ) compared with unscreened recruits. The personality trait of the conscripts did not have any impact.

We are convinced that our prediction model can be successfully adapted to any military service model and operational setting. Therefore, we believe it is too early to bid farewell to psychiatric screening systems in medical risk management.

Eysenck, H. J. (1988) Personality, stress and cancer: prediction and prophylaxis. British Journal of Medical Psychology, 61, 57-75.

Holinger, P. C., Offer, D. \& Zola, M. A. (1988) A prediction model of suicide among youth. Journal of Nervous and Mental Disease, I76, 275-279.
Jones, E., Hyams, K. \& Wessely, S. (2003) Screening for vulnerability to psychological disorder in the military: an historical inquiry. Journal of Medical Screening, 10, 40-46.

Tuhrim, S., Dambrosia, J. M., Price, T. R., et al (1988) Prediction of intracerebral hemorrhage survival. Annals of Neurology, 24, 258-263.

Wessely, S. (2005) Risk, psychiatry and the military. British Journal of Psychiatry, 186, 459-466.

World Health Organization (1992) The ICD-10 Classification of Mental Health and Behavioural Disorders: Diagnostic Criteria for Research. Geneva: WHO.

S. Vetter Centre for Disaster and Military Psychiatry, University of Zurich, Birchstrasse 3, $\mathrm{CH}-8057$ Zurich, Switzerland.

E-mail: stefan.vetter@access.unizh.ch

Author's reply: I thank Dr Vetter for his cordial letter. The question at issue is not whether or not it is possible to create a statistical model that can predict psychiatric breakdown in military recruits - that is certainly possible, as the experiences of the Second World War psychiatrists showed. The question is with what accuracy can one make such a prediction and what are the consequences for those both correctly identified and, even more importantly, those who have been incorrectly identified (the false positives). Dr Vetter does not provide sufficient information for us to make that judgement. What is needed is the sensitivity, specificity and most importantly the positive predictive value of whatever collection of variables he and his colleagues are using to determine the risk of future illness. It is this statistic that enables us to assess the utility of the proposed model.

Furthermore, we do not know what were the consequences of being labelled as at risk of psychiatric breakdown. Were these people denied military service? Switzerland is one of the increasingly few countries that still has compulsory military service. Serving in the Armed Forces is a fundamental part of the life of every Swiss citizen and enables a person to form social networks that operate for many years. Are people disadvantaged from being denied that opportunity? Given that the Swiss are also famed for their neutrality, the fall in psychiatric morbidity as a result of screening is not likely to be because those denied military service are not exposed to the risks of the battlefield. Instead it may be that their subsequent breakdown merely happens in another sector of Swiss life. Without data from a randomised controlled 